\title{
Risks and Strategies in Constructing Global Supply Chain for Fresh Food E-commerce
}

\author{
Jingxue Zhang \\ School of Management, Shanghai University, 99 Shangda Road, Shanghai, China
}

\begin{abstract}
With the expansion of global trade and technological progress, China's cross-border E-commerce trade has extended a new subdivision industry-Fresh Food E-commerce. Since its birth, China's fresh food E-commerce enterprises have developed rapidly and gradually built a diversified global supply chain system, but they are also faced with dangerous risks. This paper introduces the external risks of politics, economy and society and the internal risks represented by supplier risks, logistics risks and operation risks encountered by enterprises in the construction of global supply chain, discusses the sources of the risks, and puts forward corresponding strategies on this basis.
\end{abstract}

Keywords: Fresh food E-commerce, Global supply chain, Risk management, Strategy research.

\section{Introduction}

In the past decade, with the economic globalization and the upgrading of national consumer demand, the scope of China's cross-border trade has become more and more extensive. According to the statistical data of China's Customs, the total import and export volume of cross-border trade fluctuates, but the overall trend is rising. Among all kinds of imported products, the variety of fresh food is increasing.

Started in 2005, China's fresh food e- commerce industry has only been developing for about 10 years. 2014-2015 is the stage of its rapid development, but the competition within the industry is increasingly fierce. In order to increase product competitiveness, more and more enterprises cater to consumers, sell high-quality imported fresh food, and start to build a global supply chain.

Due to high cost and complex technology, the penetration of fresh food in the E-commerce industry is low, the development of imported fresh food is more difficult. Therefore, Chinese fresh food E-commerce enterprises face many risks in the process of building a global supply chain.

\section{The Organizational Structure and Characteristics of Global Supply Chain}

\subsection{Organizational Structure}

At present, origin sourcing is the common way to cross-border fresh products. In this mode, the products are supplied by the manufacturer, processed with freshness, and then transported to offline sites in China by international cold chain logistics. At the same time, enterprises contact customers through online E-commerce platforms, and products are delivered to customers through domestic self-established or third-party cold chain logistics.

To sum up, the components of the global supply chain constructed by fresh electricity business enterprises are: suppliers, transporters (foreign tripartite logistics + domestic tripartite logistics), fresh food E-commerce business enterprises (online platform + offline site) and customers, as shown in Figure 1. Fresh food E-commerce enterprises are the core enterprises in the supply chain.

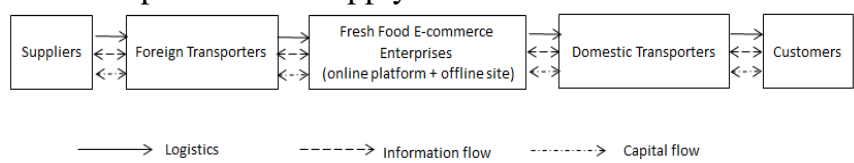

Figure 1: Global supply chain structure of Chinese fresh food E-commerce

\subsection{Organizational Characteristics}

Compared with the complex network structure formed by some manufacturing enterprises in the process of globalization development, the global supply chain of Chinese fresh food E-commerce enterprises also reflects its unique features: (1) in order to ensure the freshness of products, it is more and more flat and streamlined; (2) The length of the global supply chain has increased and the range of distribution has become wider; (3) There are more uncertain factors and higher requirements for technical operation.

The global supply chain for cross-border fresh food has been simplified in structure, but not in frequency or degree. On the contrary, with the environmental instability is gradually increasing.

\section{Risks of China's Fresh E-commerce Enterprises in Building Global Supply Chains}

Based on the analysis of structure and characteristics, the construction of global supply chain faces internal and external risks, as shown in Figure 2.

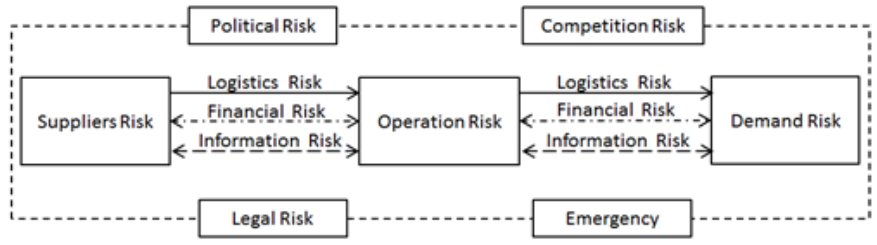

Figure 2: The risks of global supply chain 
The external risk comes from the domestic and foreign macro and micro environment, including political risk, competition risk, legal risk and emergency. Internal risks arise in the transmission process of supply chain logistics, information flow and capital flow, including supplier risk, logistics risk, core enterprise operation risk, customer demand risk, financial risk and information risk.

First, companies face serious external risks. (1) Political risk. Since commodity trade policies are restricted by regional trade organizations, the distribution of member firms in the global supply chain creates a complex political environment. (2) Competition risk. With the development of the industry, the number and scale of enterprises are constantly expanding, and the competition between enterprises is increasingly fierce. (3) Legal risks. In international procurement, the difference of national laws and regulations will also affect the contract signing and performance. (4) Emergency. Fresh products are directly affected by the natural environment. Most of the procurement sites are threatened by natural disasters. In addition, war, terrorist attacks and other emergencies will also cause the disruption of supply chain, such as COVID-19.

At the same time, companies also face internal risks. (1) Supplier risks. The complexity of supplier sources causes the instability of product supply. (2) Logistics risk. The foreign stage of transportation and domestic logistics distribution may produce risks, such as foreign worker strikes and the shortcomings of China's cold chain logistics technology. (3) Operational risks. Excessive use of promotional strategies, rapid changes in development models and poor after-sale processing can pose risks. (4) Demand risk. Imported products are difficult to match with the local market demand, and product sales are greatly affected by factors such as regional consumption level and population structure. (5) Financial risks. The fresh industry has a large amount of investment and a long payback period. Under the global supply chain, fresh products are more prone to decay and are not easy to preserve, with high logistics costs and low profits. (6) Information risks. Risks may come from information asymmetry and trading platform storage, such as supplier default and platform account theft.

\section{Analysis of Causes of Risks}

According to the analysis of the types of supply chain risks, we find that the sources of risks are mainly in three aspects, as shown in Figure 3:

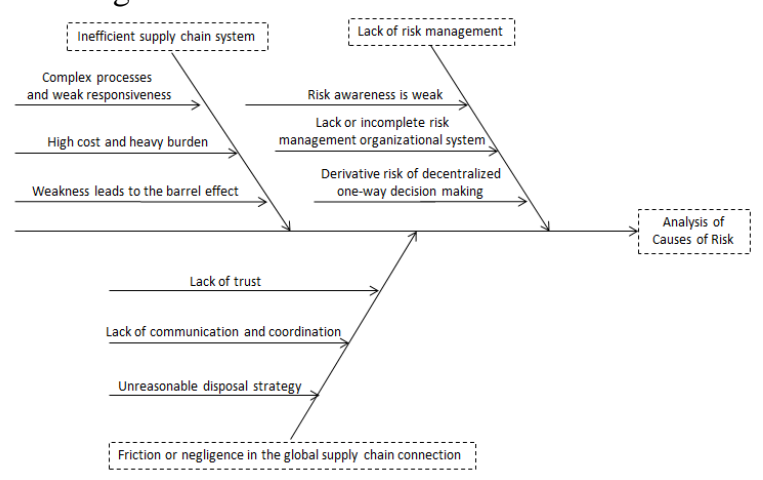

Figure 3: Analysis of causes of risks
- Failure of effective risk management in every enterprise in the supply chain.

- Problems with links between supply chain enterprises.

- The overall global supply chain is inefficient, with low capacity to respond to end-customer demand and external risks.

\subsection{Lack of Risk Management}

(1) Risk awareness is weak

Before the occurrence of risk events, enterprises lack of measures for risk prevention.

\section{(2) Lack of risk management in organizational system}

Because of the late start and small scale in the early stage, the organizational structure of the enterprise is not complete.

(3) Derivative risk of decentralized one-way decision making

In order to meet the trend of rapid development, enterprises have made a series of ways to accelerate the development process, and these decisions are radical.

4.2 Friction or Negligence in the Global Supply Chain Connection

(1) Lack of trust

Due to differences in regional culture, corporate goals and concepts, there is a lack of trust between enterprises, which makes it difficult to achieve product standardization and stable trading.

(2) Lack of communication and coordination

The running period of upstream and downstream enterprises in the supply chain is long, and there are many frictions of cooperation.

(3) Unreasonable disposal strategy

After the risk, the improper response to the problem will further aggravate the negative impact. For example, delaying processing and focusing on self-interest maximization.

\subsection{Inefficient Supply Chain System}

(1) Complex processes and weak responsiveness

It takes a long time for importing country and exporting country to reach stable cooperation and the process is complicated. The overall response speed of supply chain is slow, so it is difficult to take effective measures in a short time.

(2) High cost and heavy burden 
The whole supply chain is not promoted synchronously, but only the key links. Due to the suddenness, other nodes are also faced with high operational burden, but lack of support, which leads to increased operating costs and damages of capital chain and partnership.

(3) Weakness leads to the barrel effect

According to the survey report, China's cold chain technology is still weak, and the risk of this end link undermines previous operational results, causing waste of resources and disruption.

\section{Measures}

\subsection{Establish and Complete Supply Chain Risk Management System}

Every enterprise in the supply chain is likely to become a source of risk, which is further diffused because of transitivity. Therefore, the construction of risk management system is very necessary. According to the complex nature of supply chain risk, the construction of risk management system should include enterprise risk management system and supply chain risk management system.

\section{(1) Raise awareness of risk prevention}

First of all, we should strengthen the cognition of the specific risks and potential risk factors involved in the enterprise and the supply chain. Through carrying out communication seminars, lectures on risk topics and training equations, the causes of risk and coping methods are popularized and promoted, so as to effectively capture and integrate risk information, train risk management talents, and improve the construction intensity of risk management at the level of consciousness.

Cultivate the risk management culture that is complementary to the enterprise and the supply chain development culture, and form the rules and procedures and risk solutions that can unite the risk management organization. At the same time, in order to adapt to the characteristics of the global supply chain, in the process of gradual development and expansion, we should assign special personnel to carry out overall management according to the types and characteristics of risks encountered, so as to form a professional and efficient organizational system.

\section{(2) Improve the risk information management system}

Perfecting the construction of risk information system is one of the most basic operational supports for specific risk management projects. The virtualization of information in cross-border E-commerce trade and the decentralization of the layout of enterprises on each node put forward higher requirements for the improvement of risk information management system. The perfection of risk management information system should include two aspects: enterprise internal and global supply chain.
In order to be effective and practical, each enterprise should carry out technological upgrading and detect the evolution trend of potential risk factors in the supply chain. Enterprises should make full use of the existing feedback information to guide subsequent decisions, and should monitor the industry and other supply chains for the occurrence of risks and potential risk signs.

\section{(3) Establish a layered risk control system}

Establish a vertical and horizontal risk management organization at the decision-making level, executive level and operational level within the enterprise and the entire global supply chain system. Among them, the decision-making level is responsible for major risks and macro system; Execution level evaluates risks, reports to decision-making level, communicates and coordinates with operation level, and supervises its implementation; And the operation layer is responsible for the task execution, timely report to the superior.

\section{(4) Optimize risk management processes}

Scientific processes can improve efficiency. Risk management should include four main processes: risk identification, risk assessment, risk treatment and risk monitoring. Because risk management is a continuous dynamic change process, risk identification should pay attention to continuity and timeliness, and determine the critical control points; Then we can combine the operational objectives and risk tolerance to develop a specific control program; After the implementation of the strategy, the enterprise should record and improve, forming a benign risk management process closed loop.

\subsection{Take Reasonable Measures to Deal with Cyber Risks}

In order to deal with link risks and reduce friction, it is necessary to use effective tools to manage the interests, risks, responsibilities and business processes involved in the cooperation between enterprises, so as to realize the fairness and efficiency of division of labor and cooperation between enterprises.

\section{(1) Achieve fair income distribution}

Enterprises should distribute profits reasonably to avoid the maximization of their own interests damaging the initiative of cooperation, so as to reduce the moral hazard between supply chains.

Companies can use the Shaplely value method and game theory. Shaplely value method and modified Shaplely value method were used to allocate the contribution degree of node enterprises. Or according to the business process, establish a supply chain game model to solve the revenue.

(2) Information sharing and risk prevention

In operation, cooperative enterprises should improve the 
transparency of cooperation information, so as to realize timely information sharing, monitor risk situation, formulate risk handling mechanism and respond.

At the same time, enterprises should also make full use of the risk prevention mechanism formed by information sharing to accurately track and assign responsibilities to the links that have problems.

\section{(3) Share the risk by contract}

In order to improve the lack of trust, enterprises should establish effective contracts. On the basis of coordination and consensus, make comprehensive and systematic provisions on the cooperation methods and assessment of suppliers and logistics providers.

Guaranteed enterprise cooperation can be initially established under contract constraints, and then upgrades or changes can be made in the process of cooperation.

\section{(4) Scientifically planning business processes}

In order to smooth product logistics and solve the coordination problems, enterprises should adopt scientific methods to overall planning of the overall business process.

Through operational research, enterprises can optimize the logistics and transportation in the global supply chain as well as the establishment of storage locations and changes in storage volume, so as to realize efficient business cooperation between enterprises and reduce the coordination cost of supply chain.

\subsection{Build Together to Improve Competitiveness}

The joint construction of cross-border fresh global supply chain needs external shelter, gradually expand the business scale of the joint construction, strengthen the connection and collaboration between enterprises, and then improve the efficiency of the system, and enhance its ability to respond to external risks and customer demand risk changes.

\section{(1) Seek favorable support and simplify the process}

The composition of global supply chain is complex. Therefore, relying only on the enterprises in the supply chain may not achieve the desired effect. When designing and constructing supply chains, Chinese fresh electricity enterprises should take the initiative to cater to favorable conditions, make full use of favorable support policies, simplify business processes and reduce risks from reducing the complexity of processes.

\section{(2) Strengthen exchanges, make cooperation culture}

Enhancing communication between different regions and countries is an important way to enhance the cohesion of supply chain. Enterprises can take a combination of online and offline activities.

It's important to understand the differences; at the same time, a culture of cooperation that can be recognized by most partners should also be developed to reduce differences and frictions in the process of joint construction.

\section{(3) Mutual funds and joint decision-making}

In the process of global supply chain construction, synchronous development should be realized, the advantages of fresh electricity enterprises in social financing should be given full play, the supply chain financial mutual assistance platform should be established, and enterprise financing should be reasonably divided and used.

\section{(4) Expand new partners}

For the weak links in the supply chain, in order to deal with the projects that they are not good at and reduce the probability of risk, enterprises should adopt the combination of "self-establishment + three parties" to expand new partners. In key projects, it does not completely rely on the third party, but at the same time, it chooses professional tripartite institutions to carry out relevant cooperation, so as to make full use of its professional business ability and improve the efficiency of supply chain operation.

\section{References}

[1] Juttner U, Peck H, Christopher M, et al. Supply chain risk management: outlining an agenda for future research $[\mathrm{J}]$. International Journal of Logistics-research and Applications, 2003, 6(4): 197-210.

[2] Zhou Yongqiang, Yang Zhongzhi. Network under the competition of supply chain risk control[J]. Journal of Northwest Agriculture and Forestry University of Science and Technology (Social Science Edition), 2004 (6): 53+50-66.

[3] Maersk. How to prevent supply chain risks?[J]. Chinese Computer User, 2003(03): 21.

[4] Stauffer D. Risk: The weak link in your supply chain[J]. Harvard Management Update, 2003, 8(3): 3.

[5] Harland C, Brenchley R, Walker H L, et al. Risk in supply networks[J]. Journal of Purchasing and Supply Management, 2003, 9(2): 51-62.

[6] Zhang Xiuping, Liu Fang. Research review on supply Chain Risk Management[J]. Economic Circle, 2009(03): 46-50.

[7] Zhang Yibin, Chen Junfang. Risk identification framework and flexible control strategy of supply chain[J]. Industrial Engineering and Management, 2008(01): 47-52.

[8] Martin Bailey, Clayton Thomas. Managing risk in the supply chain $[\mathrm{J}]$. Supply Chain Management: An International Journal, 2004, 9(2): 183-196.

[9] Cohen M A, Kunreuther H. Operations risk management: Overview of Paul Kleindorfer's contributions[J]. Production and Operations Management, 2009, 16(5): 525-541.

[10] Wu T, Blackhurst J, Chidambaram V, et al. A model for inbound supply risk analysis[J]. Computers in Industry, 2006, 57(4): 350-365.

[11] Schoenherr T, Tummala V M. Best practices for the implementation of supply chain management 
Initiatives[J]. International Journal of Logistics Systems and Management, 2008, 4(4): 391-410.

[12] Adegoke Oke, Mohan Gopalakrishnan. Managing disruptions in supply chains: A case study of a retail supply chain $[\mathrm{J}]$. International Journal of Production Economics, 2009, 118(1): 168-174.

[13] Wu Jun, Li Jian, Wang Shouyang. Several important problems in supply chain risk management [J]. Journal of Management Science, 2006 (6) : 1-12.

[14] Giannakis M, Louis M. A multi-agent based system with big data processing for enhanced supply chain agility[J]. Journal of Enterprise Information Management, 2016, 29(5): 706-727.

[15] Ming Xu, Yuanyuan Cui, Meng Hu, Xinkai Xu, Zhechi Zhang, Sai Liang, Shen Qu. Supply chain sustainability risk and assessment[J]. Journal of Cleaner Production, 2019, 225: 0959-6526.

[16] Guo Xiaozhi, Zhang Xingjuan, Li Enping. Construction of B2C E-commerce enterprise supply chain risk early warning index system[J]. Enterprise Economy, 2015(05): 54-58.

[17] Gao Xiang, Jia Liangting. Research on supply chain risk of cross-border E-commerce enterprises based on structural equation Model: A case study of 167 cross-border E-commerce enterprises in Shanghai, Guangzhou, Qingdao and other cities[J]. Shanghai Economic Research, 2016(05): 76-83.

[18] Monika Mital, Manlio Del Giudice, Armando Papa. Comparing supply chain risks for multiple product categories with cognitive mapping and Analytic Hierarchy Process $[\mathrm{J}]$. Technological Forecasting and Social Change, 2018, (131): 159-170.

[19] Aivazidou E, Tsolakis N, Iakovou E, et al. The emerging role of water footprint in supply chain management: A critical literature synthesis and a hierarchical decision-making framework $[\mathrm{J}]$. Journal of Cleaner Production, 2016: 1018-1037.

[20] Zhang Qin, Shi Xiaoyan. Research on risk influencing factors of food supply chain based on analytic hierarchy Process-taking fresh food as an example[J]. Jiangsu Business Theory, 2014(10):21-24.

[21] Golnar Behzadi, Michael Justin O’Sullivan, Tava Lennon Olsen, Abraham Zhang. Agribusiness supply chain risk management: A review of quantitative decision models[J]. Omega, 2018, (79): 21-42.

[22] Chen Yu. Fresh food supply chain risk identification based on system dynamics study [J]. Journal of Logistics Technology, 2012, 31 (23): 405-407.

[23] Mehrjoo M, Pasek ZJ. Risk assessment for the supply chain of fast fashion apparel industry: a system dynamics framework[J]. International Journal of Production Research, 2016, 54(1): 28-48.

[24] Liu Yanhong. Research on Supply Chain Risk of Fresh E-commerce $[\mathrm{J}]$. China Storage and Transportation, 2016(09): 123-126.

[25] M. Er Kara, S.ü. Oktay Fürat. Supply chain risks: Literature review and a new categorization[J]. Beykent University Journal of Science and Technology, 2017, 10(1): 31-60.

[26] O. Tang, N. MusaIdentifying risk and research advancements in supply chain risk management[J]. International Journal of Production Economics, 2011, 133(1): 25-34.
[27] Aron R, Liu Y. Determinants of operational risk in global sourcing of financial services: evidence from field research $[\mathrm{J}]$. Brookings Trade Forum, 2005, 2005(1): 373-398.

[28] Wong C Y, Boonitt S, Wong C W, et al. The contingency effects of environmental uncertainty on the relationship between supply chain integration and operational performance[J]. Journal of Operations Management, 2011, 29(6): 604-615.

[29] Jaffee S, Masakure O. Strategic use of private standards to enhance international competitiveness: Vegetable exports from Kenya and elsewhere[J]. Food Policy, 2005, 30(3): 316-333.

[30] Rajagopal V, Venkatesan S P, Goh M, et al. Decision-making models for supply chain risk mitigation: A review $[\mathrm{J}]$. Computers \& Industrial Engineering, 2017: 646-682.

[31] Foxon T J, Gross R, Chase A, et al. UK innovation systems for new and renewable energy technologies: drivers, barriers and systems failures[J]. Energy Policy, 2005, 33(16): 2123-2137.

[32] Aqlan F, Lam S S. Supply chain optimization under risk and uncertainty[J]. Computers \& Industrial Engineering, 2016: 78-87.

[33] Tang C S, Tomlin B. The Power of Flexibility for Mitigating Supply Chain Risks[J]. International Journal of Production Economics, 2008, 116(1): 12-27.

[34] Yuan Feng. Trade cross-border electricity business enterprise supply chain risk analysis under the network perspective [J]. Journal of Business Research, 2021, (14): 98-101.

[35] Li Xuegong, LI Junhe. High quality development and operation mode innovation of overseas warehouse of cross-border fresh electricity business [N]. Modern Logistics News, 2020-08-03(A06).

[36] Li Xuegong, Yang Liqing. Path selection of high-quality development of Cross-border fresh E-commerce in China (part I)[N]. Modern Logistics Journal, 2020-09-02(A02).

[37] Li Xuegong, Yang Liqing. Path selection of high-quality development of Cross-border fresh E-commerce in China (part II)[N]. Modern Logistics Journal, 2020-09-07(A02).

[38] Liu Xiu-rong. Cross-border E-commerce fresh supply chain risk analysis and prevention and control [J] Guangxi Quality Supervision Review, 2019(08): 227. 